\title{
Effects of a new combination of nutraceuticals on postmenopausal symptoms and metabolic profile: a crossover, randomized, double-blind trial
}

This article was published in the following Dove Press journal:

International Journal of Women's Health

II October 2016

Number of times this article has been viewed

\author{
Valentina Trimarco' \\ Francesco Rozza ${ }^{2}$ \\ Raffaele Izzo $^{3}$ \\ Vincenzo De Leo ${ }^{4}$ \\ Valentina Cappelli ${ }^{4}$ \\ Carla Riccardi' \\ Costantino Di Carlo' \\ 'Department of Neuroscience, \\ Reproductive Sciences and Dentistry, \\ ${ }^{2}$ Department of Biomedical Sciences, \\ ${ }^{3}$ Department of Translational Medical \\ Sciences, Federico II University \\ of Naples, Naples, ${ }^{4}$ Department \\ of Molecular and Developmental \\ Medicine, University of Siena, \\ Siena, Italy
}

Objectives: This study was designed to measure the beneficial effects of a combination of nutraceutics (NUT; AkP04, Morestril ${ }^{\circledR}$, Akademy Pharma) containing soy isoflavones (80 mg), dry extract of Angelica sinensis (50 mg), dry extract of Morus alba leaf (200 mg) and magnesium $(56.25 \mathrm{mg})$ in the relief of somatic, psychological, and urogenital symptoms in postmenopausal patients, using the validated Menopause Rating Scale (MRS) and cardiovascular risk factors. Materials and methods: A total of 43 symptomatic postmenopausal women (MRS $\geq 20$ ) were enrolled in a crossover trial. After a 2 -week run-in period, patients were randomized into two arms. One arm received probiotics plus placebo over 4 weeks, followed by a 4 -week treatment with probiotics plus NUT. The second arm received probiotics plus NUT for 4 weeks, followed by a 4-week treatment with probiotics plus placebo.

Results: After the NUT period, participants showed a significant reduction in MRS score (18.4 \pm 5.4$)$ in comparison to baseline $(28.4 \pm 5)$ and the placebo period $(28 \pm 5.2)(P<0.0001$ for both comparisons). Furthermore, at the end of the active-treatment period, we observed a significant reduction in triglycerides, total and low-density lipoprotein cholesterol plasma levels and an increase in high-density lipoprotein cholesterol plasma concentration versus baseline and versus placebo (all $P<0.04$ ). Moreover, during the NUT period, we detected a significant reduction in diastolic blood pressure in comparison to baseline, but not in comparison to the placebo period. Conclusion: This NUT combination was effective for the relief of menopause symptoms in postmenopausal patients and improved their cardiovascular risk profile.

Keywords: menopause, hot flushes, lipid profile, cholesterol, phytoestrogens, soy isoflavones, cardiovascular risk

\section{Introduction}

Menopause is the physiological event in women where menstruation ceases to occur. Symptoms associated with this period of life are hot flushes and night sweats, insomnia, vaginal dryness, irregular menstrual bleeding, depressed mood, irritability, headache, forgetfulness, dizziness, deterioration in postural balance, palpitation, dry eyes, dry mouth, reduced skin elasticity, restless legs, and muscle and joint pain. ${ }^{1}$ In the following years, postmenopausal hypoestrogenism induces metabolic derangements that in turn lead to increased risk of osteoporosis and cardiovascular disease. ${ }^{1}$ While postmenopausal hormone therapy (HT) has been shown to be effective in the treatment of climacteric symptomatology and in the prevention of osteoporotic fractures, its efficacy in the prevention of cardiovascular disease is still debated. Moreover, long-term HT with administration of estrogens and progestins has been associated with an increase in the risk of breast cancer, while estrogens, alone or in association to progestins, increase
Correspondence: Raffaele Izzo Department of Translational Medical Sciences, Federico II University of Naples, Building 2, 5 Via Sergio Pansini, Naples 80131 , Italy

Tel +390817462250

Fax +390817462256

Email raffaele.izzo@unina.it
International Journal of Women's Health 2016:8 58I-587

(c) (1) \& () 2016 Trimarco et al. This work is published and licensed by Dove Medical Press Limited. The full terms of this license are available at https://www.dovepress.com/terms.php (c) $\mathrm{BY}$ and incorporate the Creative Commons Attribution - Non Commercial (unported, v3.0) License (http://creativecommons.org/licenses/by-nc/3.0/). By accessing the work you hereby accept the Terms. Non-commercial uses of the work are permitted without any further permission from Dove Medical Press Limited, provided the work is properly attributed. For permission for commercial use of this work, please see paragraphs 4.2 and 5 of our Terms (https://www.dovepress.com/terms.php). 
the risk of thrombosis. ${ }^{2}$ As a consequence, many women favor the use of nonhormonal therapies to treat menopause-related symptoms and prevent the health risks associated with postmenopausal hypoestrogenism. ${ }^{3}$ Among these nonhormonal treatments, a pivotal role is played by nutraceutics (NUT), which are concentrated forms of presumed bioactive substances originally derived from foods but now present in a nonfood matrix used to enhance health in dosages exceeding those obtainable in normal food, and thus characterized by a very low probability of adverse side effects.

Phytoestrogens are plant compounds with estrogen-like biological activity and have been proposed as a replacement to estrogen deficiency consecutive to menopause. For several years, a large volume of controversial scientific literature has been dealing with the efficacy of phytoestrogens in menopausal treatment.

There are three main classes of phytoestrogens: isoflavones, coumestans, and lignans, which occur in either plants or their seeds. A single plant often contains more than one class of phytoestrogen. The major isoflavones, genistein and daidzein, commonly exist as inactive glucosides. ${ }^{4}$ They are also derived from precursors, biochanin A, and formononetin, which are converted to genistein and daidzein, respectively, after breakdown by intestinal glucosidases. ${ }^{5}$ In humans, after consumption of isoflavones, complex enzymatic metabolic conversions occur in the gastrointestinal tract, resulting in the formation of heterocyclic phenols with a close similarity in structure to estrogens. ${ }^{6}$ Absorbed phytoestrogen metabolites undergo enterohepatic circulation and may be excreted in bile, ${ }^{7}$ deconjugated by intestinal flora, reabsorbed, reconjugated by the liver, and excreted in the urine. ${ }^{8}$ It has been demonstrated that intestinal microflora play a pivotal role in the metabolism and bioavailability of isoflavones. ${ }^{6,9}$ Furthermore, the concentration of different phytoestrogen metabolites varies widely between individuals, even when a controlled quantity of isoflavone supplement is administered, since their metabolism is influenced by other components of the diet, thus accounting for the conflicting results of clinical studies aimed at assessing the effects of phytoestrogen supplements on menopausal symptoms. In particular, a high carbohydrate milieu causes increased intestinal fermentation, which results in more extensive biotransformation of phytoestrogens. Therefore, since dietary phytoestrogen metabolism is predominantly determined by gastrointestinal flora ${ }^{6,10}$ and carbohydrate content, in order to maximize the bioavailability of isoflavones we combined this treatment with the administration of fructo-oligosaccharides and Bifidobacterium breve to stabilize the intestinal bacteria.
As a double-blind, placebo-controlled, crossover, randomized trial, this study was designed to assess the beneficial effects of a combination of NUT (soy isoflavones [80 $\mathrm{mg}$ ], dry extract of Angelica stem [50 mg], dry extract of Morus alba leaf [200 mg], and magnesium [56.25 mg]) administered in combination with B. breve B3 (ATCC 15700; AkP04, MoreStril, Akademy Pharma) in the relief of somatic, psychological, and urogenital symptoms in postmenopausal patients, using the validated Menopause Rating Scale (MRS), a scale developed to measure the severity of aging-symptoms and their impact on health-related quality of life. Moreover, we also evaluated the effects of this combination of NUT on cardiovascular risk factors.

\section{Materials and methods}

This was a multicenter, 10-week, randomized, doubleblind, crossover, placebo-controlled study. In the screening visit, a physician administered the MRS and assessed inclusion and exclusion criteria. During the study period, all subjects consumed probiotics (B. breve B3 ATCC 15700, 1 trillion colony-forming units) plus placebo or the same probiotics plus a combination of NUT according to a crossover randomized double-blind design, so that all patients after a 2-week run-in period received both study treatments, each for 4 weeks. Such a short treatment period was chosen to test the possibility that the simultaneous administration of fructo-oligosaccharides and $B$. breve may maximize the bioavailability of isoflavones and accelerate their clinical effects by stabilizing the intestinal bacteria.

The enrollment was conducted in the Menopause Outpatient Clinic of the Federico II University of Naples and in a similar clinic of the University of Siena, according to a predetermined randomization table of a crossover design. Inclusion criteria were healthy postmenopausal women (FSH >40 mIU/mL), age 50-60 years, and MRS score $\geq 20$. Exclusion criteria were use of any postmenopausal HT, including selective estrogen-receptor modulators, tibolone, and NUT, for menopausal symptoms in the last 6 months, dyslipidemia requiring statin therapy, and any serious chronic or acute medical or surgical condition (ie, acute and chronic cardiovascular disease and cancer).

The primary end point was the improvement of postmenopause-related symptoms evaluated by MRS. Secondary end points were changes in lipid profile. The study was conducted in accordance with the guidelines of the Declaration of Helsinki, and was approved by the ethics committee of the Federico II University of Naples (protocol 
number 175/15). Written informed consent was obtained from each subject enrolled in the study.

\section{Protocol}

After the screening visit and recruitment, patients were given dietary counseling by an expert dietician according to their clinical conditions, and received placebo for 2 weeks. At the end of this run-in period, patients were randomized into two arms assigned to receive: 1) probiotics plus placebo for 4 weeks followed by a 4 -week treatment with probiotics plus NUT or 2) probiotics plus NUT for 4 weeks followed by a 4-week treatment with probiotics plus placebo. At inclusion and after the first and the second phase of the study, we measured systolic blood pressure (SBP) and diastolic BP (DBP), heart rate, waist girth, lipid and glucose profile assessed by triglycerides, total and high-density lipoprotein (HDL) cholesterol, and fructosamine plasma levels (Figure 1). All measurements were performed at baseline and at the end of each of the two study steps. Simultaneously, MRS score was determined. Fructosamine was preferred to $\mathrm{HbA}_{1 \mathrm{c}}$ as a marker of short-term (2-4 weeks) glycemic control. It has been strongly associated with incident diabetes and its microvascular complications. ${ }^{11}$

\section{Measurements and definitions}

Blood samples for plasma fructosamine and lipid concentrations were obtained in the fasting state and the assay performed by standard methods, in quality-certified institutional labs, using the same assays in the two centers (Abbot Clinical Chemistry, according to the Cholesterol Reference Method
Laboratory Network). In particular, lipid concentrations were determined by enzymatic methodology and fructosamine levels by kinetic colorimetric methods. Waist circumference was measured at each visit midway between the lowest rib and the iliac crest using an anthropometric tape. SBP and DBP were measured by standard sphygmomanometer after 5 minutes in the supine position, according to the guidelines of the European Society of Hypertension/European Society of Cardiology. ${ }^{12}$

\section{MRS}

The MRS consists of eleven items categorized into three subscales: sweating/hot flushes, heart discomfort, sleep problems, joint and muscle problems, categorized as somatovegetative symptoms; depressive mood, irritability, anxiety, and physical/mental exhaustion, categorized as psychological symptoms; and sexual problems, bladder problems, and vaginal dryness, categorized as urogenital symptoms. Severity was rated and scored as none ( 0 points), mild (1 point), moderate ( 2 points), severe ( 3 points), and very severe (4 points). The total score ranges from 0 to $44 .{ }^{13,14}$

\section{Statistical analysis}

From a clinical point of view, we would consider useful a treatment that allows a decrease in MRS score of 8 points. Therefore, setting the lower- and upper-equivalence limits to 1 , $\alpha=0.05 \%$ (type I error), and $\beta$-error equal to $10 \%$ (type II error; power $90 \%$ ), and according to a crossover design results in a sample size equal to 38 subjects. Considering a possible dropout close to $5 \%$, we assumed a total sample size of 43 subjects.

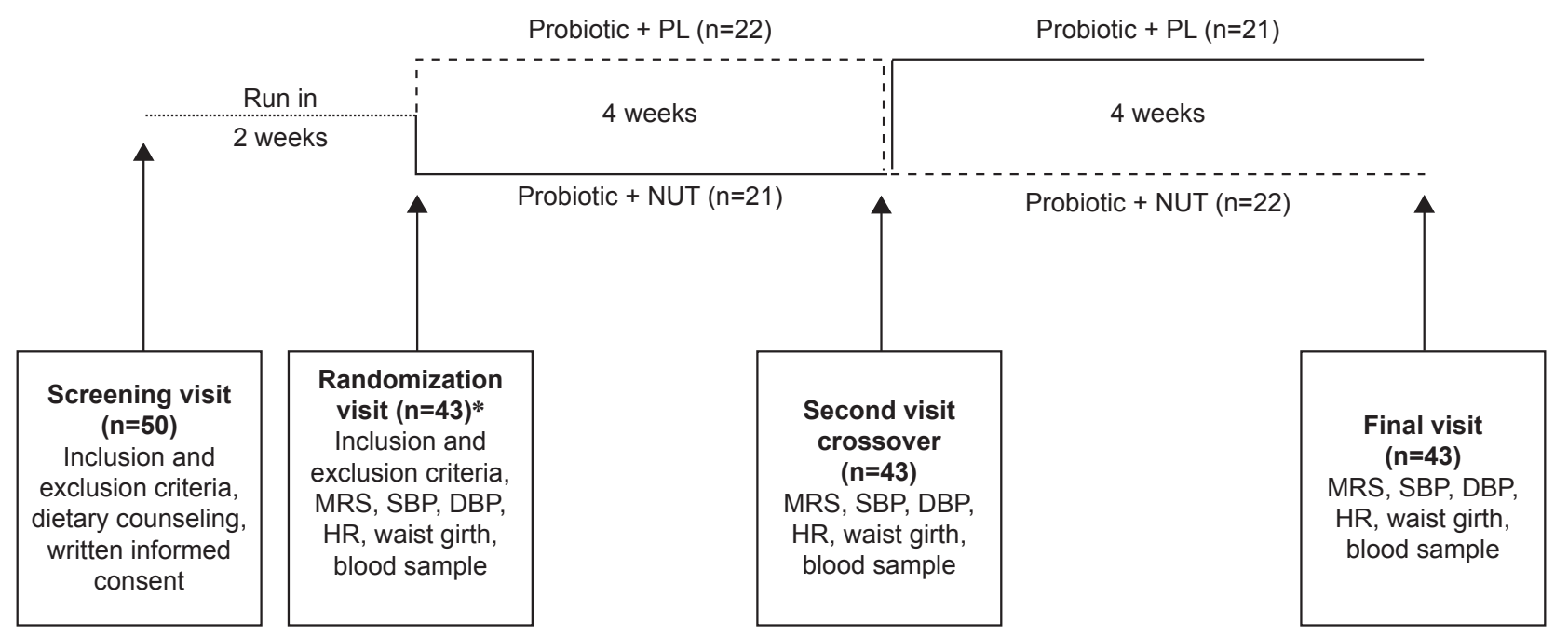

Figure I Flowchart of the study.

Note: *Seven participants were excluded on account of an MRS $<20$.

Abbreviations: PL, placebo; NUT, nutraceutics; SBP, systolic blood pressure; DBP, diastolic blood pressure; HR, heart rate; HDL, high-density lipoprotein; LDL, low-density lipoprotein; MRS, Menopause Rating Scale. 
Table I Baseline demographic and clinical characteristics of the study population divided by initial treatment

\begin{tabular}{|c|c|c|c|}
\hline & $\begin{array}{l}\text { Starting with } \\
\text { probiotics + PL }(n=22)\end{array}$ & $\begin{array}{l}\text { Starting with } \\
\text { probiotics + NUT (n=2l) }\end{array}$ & $P$-value \\
\hline Age (years) & $55.3 \pm 3.8$ & $55.5 \pm 3.3$ & NS \\
\hline $\mathrm{SBP}(\mathrm{mmHg})$ & $130.8 \pm 17.2$ & $121.8 \pm 11.8$ & NS \\
\hline $\mathrm{DBP}(\mathrm{mmHg})$ & $78.8 \pm 5.7$ & $76.1 \pm 6.5$ & NS \\
\hline Waist circumference $(\mathrm{cm})$ & $88.4 \pm 13$ & $89.1 \pm 14.7$ & NS \\
\hline Total cholesterol $(\mathrm{mmol} / \mathrm{L})$ & $5.8 \pm 0.85$ & $5.5 \pm 0.79$ & NS \\
\hline HDL cholesterol (mmol/L) & $1.5 \pm 0.38$ & $1.52 \pm 0.33$ & NS \\
\hline LDL cholesterol (mmol/L) & $3.6 I \pm 0.8 I$ & $3.4 \pm 0.7$ & NS \\
\hline Triglycerides (mmol/L) & $1.5 \pm 0.64$ & $1.3 \pm 0.64$ & NS \\
\hline Fructosamine $(\mu \mathrm{mol} / \mathrm{L})$ & $221.6 \pm 35.6$ & $222.5 \pm 38.3$ & NS \\
\hline MRS (score) & $27.8 \pm 5.9$ & $28.9 \pm 4$ & NS \\
\hline
\end{tabular}

Note: Each value represents mean \pm SD.

Abbreviations: PL, placebo; NUT, nutraceutics; SBP, systolic blood pressure; DBP, diastolic blood pressure; HDL, high-density lipoprotein; LDL, low-density lipoprotein; MRS, Menopause Rating Scale; NS, not significant; SD, standard deviation.

Data were analyzed using SPSS (version 23.0; IBM Corporation, Armonk, NY, USA) and expressed as mean \pm standard deviation. All variables deviating from normal distribution were log-transformed before parametric statistics were calculated. Differences in the considered variables among baseline, placebo, and NUT treatment were determined using single-group analysis of variance for repeated measures with deviation contrast from baseline for trend analysis and Scheffé's procedure for post hoc comparison. Significance was set at $P<0.05$. The end points were improvement in postmenopause-related symptoms evaluated by MRS and improvement in lipid profile.

\section{Results}

Fifty women were selected for the run-in period. Seven were excluded on account of an MRS score $<20$, and 43 were enrolled in the randomized study (mean age $55.4 \pm 3.5$ years) (Figure 1). Baseline demographic and clinical characteristics of the study population are reported in Table 1. No adverse events were reported. All enrolled patients completed the study.

In order to rule out the possibility of a carryover effect of the first treatment on the second due to lack of a washout period between the two study periods, we compared the paired difference of MRS scores from baseline after first-line intervention and second-line intervention (Table 2). In the light of the lack of difference between these values, we cumulated the data obtained with active treatment and placebo for the statistical analysis.

After the NUT period, participants showed a significant reduction in MRS score (18.4 \pm 5.4$)$ in comparison to baseline $(28.4 \pm 5)$ and the placebo period $(28 \pm 5.2)(P<0.0001$ for both comparisons) (Figure 2). In particular, when the three different categories of menopausal symptoms were considered separately, a clinical and statistically significant difference was found in all cases (Table 3).

Table 4 shows clinical characteristics of the study population, lipid profile, BP, and fructosamine plasma concentration at baseline, at the end of the placebo period, and after treatment with NUT combination. Participants showed an improvement in lipid profile during treatment with NUT combination. In particular, at the end of the active-treatment period, we observed a significant reduction in triglycerides and total and low-density lipid (LDL)-cholesterol plasma levels, and an increase in HDL-cholesterol plasma concentration versus baseline and versus placebo (all $P<0.04$ ). Moreover, during the NUT period, we detected a significant reduction in DBP in comparison to baseline, but not in comparison to the placebo period. No statistically significant difference was detectable among the absolute values of

Table 2 MRS score compared from baseline after first-line intervention and second-line intervention

\begin{tabular}{lll}
\hline & $\begin{array}{l}\text { Second visit } \\
\text { (\% vs randomization visit) }\end{array}$ & $\begin{array}{l}\text { Final visit } \\
\text { (\% vs second visit) }\end{array}$ \\
\hline Starting with probiotic + PL ( $\mathrm{n}=22)$ & 0.4 & -35.0 \\
Starting with probiotic + NUT $(\mathrm{n}=21)$ & -31.0 & -1.3 \\
\hline
\end{tabular}

Notes: $P=0.705$ when comparing second visit of group starting with probiotic $+P L$ versus final visit of group starting with probiotic + NUT; $P=0.532$ when comparing final visit of group starting with probiotic + PL versus second visit of group starting with probiotic + NUT.

Abbreviations: MRS, Menopause Rating Scale; PL, placebo; NUT, nutraceutics. 


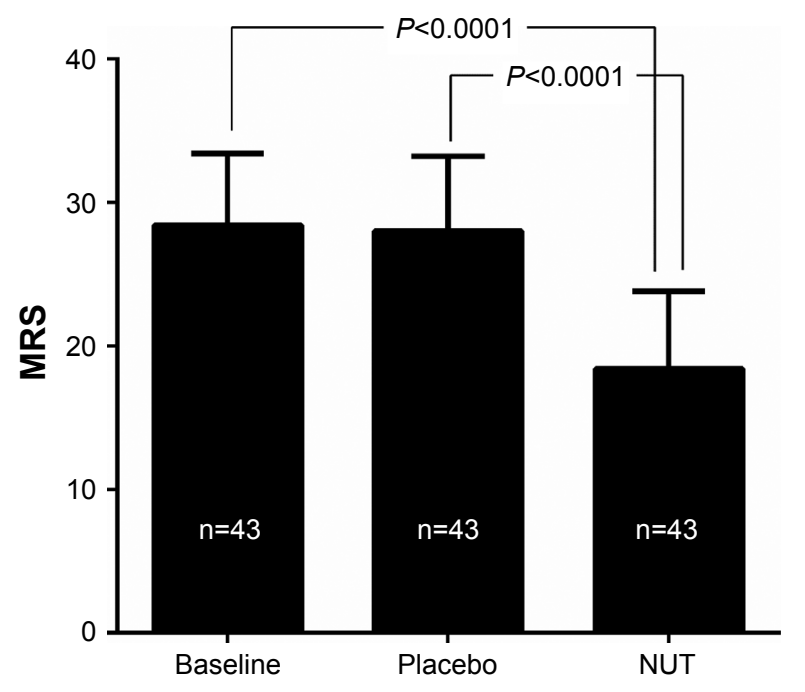

Figure 2 MRS score after placebo and NUT period.

Note: Data obtained with active treatment and placebo were cumulated for the statistical analysis.

Abbreviations: MRS, Menopause Rating Scale; NUT, nutraceutics.

SBP, waist circumference, and fructosamine or of interaction treatment $\times$ time for any dependent variable.

\section{Discussion}

Several randomized controlled trials have shown that in postmenopausal women, ${ }^{15-18}$ soy and other natural compounds improve quality of life and glycemic control, ${ }^{19}$ but are not able to improve lipid profile, ${ }^{19}$ which is frequently altered in this condition. Our randomized, crossover, double-blind study showed that 4 weeks of treatment with our NUT combination was able to improve symptoms related to menopause and consequently quality of life ${ }^{20}$ and lipid profile. Previous authors ${ }^{20}$ have reported a reduction in frequency of hot flushes after 2 weeks using soy supplementation, while other hot-flush trials used a longer observation period. ${ }^{21-23}$ Therefore, we performed 4 weeks of treatment with our supplement, which was effective. Whether this fast positive result may be ascribed to nongenomic estrogenic effects of the compound or to a nonestrogen receptor-mediated mechanism of action (similar to the effects of selective serotonin-reuptake inhibitors and serotoninnorepinephrine reuptake inhibitors) remains to be determined.
A number of clinical trials of soy foods have been conducted in postmenopausal women, aimed at evaluating the effects on hot flushes and vaginal cytology. Results and conclusions have been variable but promising with regard to an estrogenic effect; however, strong placebo effects have been observed. ${ }^{21-23}$ In order to rule out such a possibility, we used a crossover placebo-controlled randomized protocol, ${ }^{6}$ we focused on symptoms related to menopause as assessed by the MRS. The observation that MRS scores did not change during treatment with probiotics plus placebo seems to support the conclusion that the improvement in MRS score observed during treatment with the probiotic and NUT combination was entirely due to the latter component.

Estrogen deficiency is associated with significant alterations in lipoprotein metabolism, with serum cholesterol concentrations increasing markedly in the postmenopausal years. Animal studies have shown that substituting soy protein for dietary animal protein reduces serum total and LDLcholesterol concentrations. ${ }^{24}$ A meta-analysis of 38 clinical studies concluded that an average intake in soy protein of $47 \mathrm{~g}$ was associated with a mean reduction in total serum cholesterol of $9.3 \%$, whereas LDL cholesterol decreased an average of $12.9 \%{ }^{25}$ and the effect on HDL cholesterol was negligible.

In our study, the daily intake of isoflavones was $80 \mathrm{mg}$, and we detected a reduction in LDL cholesterol greater than $20 \%$ of the basal value, which was accompanied by a statistically significant decrease in triglycerides and an increase in HDL cholesterol similar in magnitude to that described by Setchell and Cassidy, ${ }^{26}$ when $60 \mathrm{~g}$ of soy protein was given daily over a 4-week period in postmenopausal women. The exact mechanism of the hypocholesterolemic effect of soy protein remains elusive, but a linear dose-response relationship has been observed between isoflavone content and cholesterol reduction. ${ }^{26}$ Furthermore, the hypocholesterolemic effect is lost when isoflavones are removed from the soy protein by alcohol extraction. ${ }^{27}$ However, it is also noteworthy that the combination of NUT used in the present study included $M$. alba, which has been proposed for

Table 3 MRS divided into different categories of menopausal symptoms at baseline and at the end of the two study periods

\begin{tabular}{|c|c|c|c|c|c|c|}
\hline & $\begin{array}{l}\text { Baseline } \\
(n=43)\end{array}$ & $\begin{array}{l}\text { Placebo } \\
(n=43)\end{array}$ & $\begin{array}{l}\text { NUT combination } \\
(n=43)\end{array}$ & $\begin{array}{l}P<\text { (placebo } \\
\text { vs baseline) }\end{array}$ & $\begin{array}{l}\mathbf{P}<\text { (NUT } \\
\text { vs baseline) }\end{array}$ & $\begin{array}{l}P<\text { (NUT } \\
\text { vs placebo) }\end{array}$ \\
\hline Urogenital symptoms & $6.5 \pm 1.9$ & $6.9 \pm 1.8$ & $4.9 \pm 1.9$ & NS & 0.0001 & 0.0001 \\
\hline Psychological symptoms & $13.4 \pm 2.9$ & $12.8 \pm 3.4$ & $8.2 \pm 2.8$ & NS & 0.0001 & 0.0001 \\
\hline Somatovegetative symptoms & $8.4 \pm 1.9$ & $8.0 \pm 2.2$ & $5.4 \pm 1.9$ & NS & 0.0001 & 0.0001 \\
\hline
\end{tabular}

Note: Each value represents mean \pm SD.

Abbreviations: MRS, Menopause Rating Scale; NUT, nutraceutics; NS, not significant; SD, standard deviation. 
Table 4 Blood pressure, lipid, and glucose profile at baseline and at the end of the two study periods

\begin{tabular}{|c|c|c|c|c|c|c|}
\hline & $\begin{array}{l}\text { Baseline } \\
(n=43)\end{array}$ & $\begin{array}{l}\text { Placebo } \\
(n=43)\end{array}$ & $\begin{array}{l}\text { NUT } \\
\text { combination }\end{array}$ & $\begin{array}{l}\boldsymbol{P}<\text { (placebo } \\
\text { vs baseline) }\end{array}$ & $\begin{array}{l}\mathbf{P}<\text { (NUT } \\
\text { vs baseline) }\end{array}$ & $\begin{array}{l}P<\text { (NUT } \\
\text { vs placebo) }\end{array}$ \\
\hline SBP (mmHg) & $126.2 \pm 15.2$ & $128.4 \pm 13$ & $126.4 \pm 10.3$ & NS & NS & NS \\
\hline $\mathrm{DBP}(\mathrm{mmHg})$ & $77.5 \pm 6.3$ & $76.3 \pm 6$ & $74.6 \pm 6.6$ & NS & 0.026 & NS \\
\hline Waist circumference (cm) & $88.7 \pm 13.8$ & $88.9 \pm 13.8$ & $88.3 \pm 13.5$ & NS & NS & NS \\
\hline Total cholesterol (mmol/L) & $5.7 \pm 0.83$ & $5.6 \pm 0.76$ & $4.9 \pm 0.71$ & NS & 0.0001 & 0.0001 \\
\hline HDL cholesterol (mmol/L) & $1.5 \pm 0.35$ & $1.5 \pm 0.33$ & $1.6 \pm 0.37$ & NS & 0.0001 & 0.01 \\
\hline LDL cholesterol (mmol/L) & $3.5 \pm 0.76$ & $3.5 \pm 0.77$ & $2.8 \pm 0.69$ & NS & 0.0001 & 0.0001 \\
\hline Triglycerides (mmol/L) & $1.4 \pm 0.65$ & $1.3 \pm 0.57$ & $1.2 \pm 0.43$ & NS & 0.016 & 0.036 \\
\hline Fructosamine $(\mu \mathrm{mol} / \mathrm{L})$ & $222.0 \pm 36.6$ & $219.6 \pm 31.5$ & $210.9 \pm 34.4$ & NS & NS & NS \\
\hline
\end{tabular}

Note: Each value represents mean \pm SD.

Abbreviations: NUT, nutraceutics; SBP, systolic blood pressure; DBP, diastolic blood pressure; HDL, high-density lipoprotein; LDL, low-density lipoprotein; NS, not significant; SD, standard deviation.

the treatment of dyslipidemia according to the results of a double-blind randomized trial versus placebo. ${ }^{28}$

A final observation is that while cardiovascular diseases are the main cause of death in postmenopausal women, they are relatively rare before the onset of menopause, and notably their incidence begins to increase at exactly the same time as hot flushes make their appearance. Recent evidence suggests that the appearance of flushing may not only be a "nuisance symptom", but also a marker of underlying cardiovascular diseases. ${ }^{29}$ Indeed, postmenopausal women with hot flushes were shown to have lower flow-mediated dilation and increased calcified plaques in the aorta. ${ }^{30}$ Moreover, the severity of hot flushes was highly related to flow-mediated dilation in another study. ${ }^{31}$ Finally, a significant positive association has been demonstrated between coronary events and night sweats. ${ }^{32}$ While it is not clear which mechanisms underlie this association between vasomotor symptoms and cardiovascular risk factors, NUT seems to be active in both the treatment of hot flushes and reducing cardiovascular risk factors.

\section{Conclusion}

The mechanisms underlying the health benefits of the combination of NUT used in our study remain a major challenge. The results of the present study seem to confirm the beneficial effects of this NUT combination and support its use in larger studies aimed at assessing the role of isoflavones combined with fructo-oligosaccharides and $B$. breve in the treatment of menopause syndrome.

\section{Limitations}

The lack of a period of washout between the treatments represents a limitation of this study. However, the observation (Table 2) that there was no statistically significant difference between changes in MRS values after the first-line intervention and the second-line intervention suggests that there was no carryover effect for MRS scores.

\section{Acknowledgment}

The authors are indebted to Professor Giovanni de Simone, the expert statistician who supervised and approved the statistical analysis.

\section{Disclosure}

The abstract of this paper was presented at the 14th National Congress of the Italian Society of Cardiovascular Prevention (SIPREC), Naples, March 17-19, 2016 as a poster presentation with interim findings. It was published in High Blood Pressure \& Cardiovascular Prevention (2016;23[2]:155-174). The authors report no conflicts of interest in this work.

\section{References}

1. Moilanen J, Aalto AM, Hemminki E, Aro AR, Raitanen J, Luoto R. Prevalence of menopause symptoms and their association with lifestyle among Finnish middle-aged women. Maturitas. 2010;67(4):368-374.

2. Rossouw JE, Anderson GL, Prentice RL, et al. Risks and benefits of estrogen plus progestin in healthy postmenopausal women: principal results from the Women's Health Initiative randomized controlled trial. JAMA. 2002;288(3):321-333.

3. Freeman MP, Hibbeln JR, Silver M, et al. Omega-3 fatty acids for major depressive disorder associated with the menopausal transition: a preliminary open trial. Menopause. 2011;18(3):279-284.

4. Axelson M, Sjövall J, Gustafsson BE, Setchell KD. Soya: a dietary source of the non-steroidal oestrogen equol in man and animals. J Endocrinol. 1984;102(1):49-56.

5. Rowland IR. Role of the Gut Flora in Toxicity and Cancer. London: Academic Press; 1988.

6. Setchell KD, Borriello SP, Hulme P, Kirk DN, Axelson M. Nonsteroidal estrogens of dietary origin: possible roles in hormone-dependent disease. Am J Clin Nutr. 1984;40(3):569-578.

7. Axelson M, Setchell KD. The excretion of lignans in rats: evidence for an intestinal bacterial source for this new group of compounds. FEBS Lett. 1981;123(2):337-342. 
8. Adlercreutz H, Fotsis T, Bannwart C, et al. Determination of urinary lignans and phytoestrogen metabolites, potential antiestrogens and anticarcinogens, in urine of women on various habitual diets. J Steroid Biochem. 1986;25(5B):791-797.

9. Borriello SP, Setchell KD, Axelson M, Lawson AM. Production and metabolism of lignans by the human faecal flora. J Appl Bacteriol. 1985; 58(1):37-43.

10. Atkinson C, Frankenfeld CL, Lampe JW. Gut bacterial metabolism of the soy isoflavone daidzein: exploring the relevance to human health. Exp Biol Med (Maywood). 2005;230(3):155-170.

11. Selvin E, Rawlings AM, Grams M, et al. Fructosamine and glycated albumin for risk stratification and prediction of incident diabetes and microvascular complications: a prospective cohort analysis of the Atherosclerosis Risk in Communities (ARIC) study. Lancet Diabetes Endocrinol. 2014;2(4):279-288.

12. Mancia G, Fagard R, Narkiewicz K, et al. 2013 ESH/ESC guidelines for the management of arterial hypertension. Eur Heart J. 2013; 34(28):2159-2219.

13. Heinemann K, Ruebig A, Potthoff P, et al. The Menopause Rating Scale (MRS) scale: a methodological review. Health Qual Life Outcomes. 2004;2:45

14. Heinemann LA, DoMinh T, Strelow F, Gerbsch S, Schnitker J, Schneider HP. The Menopause Rating Scale (MRS) as outcome measure for hormone treatment? A validation study. Health Qual Life Outcomes. 2004;2:67.

15. Atteritano M, Mazzaferro S, Bitto A, et al. Genistein effects on quality of life and depression symptoms in osteopenic postmenopausal women: a 2-year randomized, double-blind, controlled study. Osteoporos Int. 2014; 25(3):1123-1129.

16. D’Anna R, Cannata ML, Atteritano M, et al. Effects of the phytoestrogen genistein on hot flushes, endometrium, and vaginal epithelium in postmenopausal women: a 1-year randomized, double-blind, placebocontrolled study. Menopause. 2007;14(4):648-655.

17. Carmignani LO, Pedro AO, Montemor EB, Arias VA, Costa-Paiva LH Pinto-Neto AM. Effects of a soy-based dietary supplement compared with low-dose hormone therapy on the urogenital system: a randomized, double-blind, controlled clinical trial. Menopause. 2015;22(7): 741-749.

18. Newton KM, Reed SD, LaCroix AZ, Grothaus LC, Ehrlich K, Guiltinan J. Treatment of vasomotor symptoms of menopause with black cohosh, multibotanicals, soy, hormone therapy, or placebo: a randomized trial. Ann Intern Med. 2006;145(12):869-879.

19. Atteritano M, Marini H, Minutoli L, et al. Effects of the phytoestrogen genistein on some predictors of cardiovascular risk in osteopenic, postmenopausal women: a two-year randomized, double-blind, placebocontrolled study. J Clin Endocrinol Metab. 2007;92(8):3068-3075.
20. Gartoulla P, Bell RJ, Worsley R, Davis SR. Moderate-severely bothersome vasomotor symptoms are associated with lowered psychological general wellbeing in women at midlife. Maturitas. 2015;81(4): 487-492.

21. Albertazzi P, Pansini F, Bonaccorsi G, Zanotti L, Forini E, De Aloysio D. The effect of dietary soy supplementation on hot flushes. Obstet Gynecol. 1998;91(1):6-11.

22. Baird DD, Umbach DM, Lansdell L, et al. Dietary intervention study to assess estrogenicity of dietary soy among postmenopausal women. J Clin Endocrinol Metab. 1995;80(5):1685-1690.

23. Murkies AL, Lombard C, Strauss BJ, Wilcox G, Burger HG, Morton MS. Dietary flour supplementation decreases post-menopausal hot flushes: effect of soy and wheat. Maturitas. 2008;61(1-2):27-33.

24. Sirtori CR, Even R, Lovati MR. Soybean protein diet and plasma cholesterol: from therapy to molecular mechanisms. Ann N Y Acad Sci. 1993;676:188-201.

25. Anderson JW, Johnstone BM, Cook-Newell ME. Meta-analysis of the effects of soy protein intake on serum lipids. N Engl J Med. 1995; 333(5):276-282.

26. Setchell KD, Cassidy A. Dietary isoflavones: biological effects and relevance to human health. J Nutr. 1999;129(3):758S-767S.

27. Crouse JR 3rd, Morgan T, Terry JG, Ellis J, Vitolins M, Burke GL. A randomized trial comparing the effect of casein with that of soy protein containing varying amounts of isoflavones on plasma concentrations of lipids and lipoproteins. Arch Intern Med. 1999;159(17):2070-2076.

28. Trimarco V, Izzo R, Stabile E, et al. Effects of a new combination of nutraceuticals with Morus alba on lipid profile, insulin sensitivity and endothelial function in dyslipidemic subjects: a cross-over, randomized, double-blind trial. High Blood Press Cardiovasc Prev. 2015 22(2):149-154.

29. Sassarini J, Lumsden MA. Vascular function and cardiovascular risk factors in women with severe flushing. Maturitas. 2015;80(4): 379-383.

30. Thurston RC, Sutton-Tyrrell K, Everson-Rose SA, Hess R, Matthews KA. Hot flashes and subclinical cardiovascular disease: findings from the Study of Women's Health Across the Nation Heart Study. Circulation. 2008;118(12):1234-1240.

31. Bechlioulis A, Kalantaridou SN, Naka KK, et al. Endothelial function, but not carotid intima-media thickness, is affected early in menopause and is associated with severity of hot flushes. J Clin Endocrinol Metab. 2010;95(3):1199-1206

32. Gast GC, Pop VJ, Samsioe GN, et al. Vasomotor menopausal symptoms are associated with increased risk of coronary heart disease. Menopause. 2011;18(2):146-151.
International Journal of Women's Health

\section{Publish your work in this journal}

The International Journal of Women's Health is an international, peerreviewed open-access journal publishing original research, reports, editorials, reviews and commentaries on all aspects of women's healthcare including gynecology, obstetrics, and breast cancer. The manuscript management system is completely online and includes

\section{Dovepress}

a very quick and fair peer-review system, which is all easy to use. Visit http://www.dovepress.com/testimonials.php to read real quotes from published authors. 